\title{
Preparation and characterization of acellular adipose tissue matrix using a combination of physical and chemical treatments
}

\author{
MEI SONG ${ }^{1}$, YI LIU ${ }^{1}$ and LING HUI ${ }^{2}$ \\ ${ }^{1}$ Burns and Plastic Surgery Center, General Hospital of Lanzhou Military Command of The People's Liberation Army, \\ Institute of Orthopedics of Gansu Province; ${ }^{2}$ Department of Clinical Laboratories, General Hospital of \\ Lanzhou Military Command of The People's Liberation Army, Key Laboratory of Stem Cells and \\ Gene Medicine of Gansu Province, Lanzhou, Gansu 730050, P.R. China
}

Received February 19, 2016; Accepted May 4, 2017

DOI: $10.3892 / \mathrm{mmr} .2017 .7857$

\begin{abstract}
Decellularized adipose extracellular matrix (ECM) has been used in the clinic to support the regeneration of adipose tissues. The methods used to produce adipose tissue ECM scaffolds exhibit distinct effects upon the structural and functional components of the resultant scaffold material. The current study presents an acellular ECM scaffold from human adipose tissues derived using successive physical and chemical treatments, including repeated freeze-thaw cycles followed by centrifugation, polar solvent extraction and enzymatic digestion. Cellular components, including nucleic acids were effectively removed without significant disruption of the morphology or structure of the ECM. The compositions of major ECM components were evaluated, including acid/pepsin soluble collagen, sulfated glycosaminoglycan and laminin. The decellularized ECM exhibited satisfactory mechanical properties. Cell seeding experiments involving human adipose-derived stem cells indicated that the decellularized ECM provided an inductive microenvironment for adipogenesis without the need for exogenous differentiation factors. Higher levels of glycerol-3-phosphate dehydrogenase activity were observed among induced cells in the ECM scaffolds when compared with induced cells in collagen type I scaffolds. In conclusion, the results suggested that the decellularized ECM, containing biological and chemical cues of native human ECM, may be an ideal scaffold material for autologous and allograft tissue engineering.
\end{abstract}

Correspondence to: Dr Yi Liu, Burns and Plastic Surgery Center, General Hospital of Lanzhou Military Command of The People's Liberation Army, Institute of Orthopedics of Gansu Province, 333 South Riverside Road, Lanzhou, Gansu 730050, P.R. China E-mail: liuyi196402@126.com

Key words: adipose tissue engineering, extracellular matrix, decellularization, scaffold, adipose-derived stem cell

\section{Introduction}

Several surgical options are available for the repair of adipose tissues following trauma or resection, and these options generally involve autologous tissue transplantation. Although these methods are generally sufficient for tissue repair, they are associated with a number of limitations regarding the long-term survival and functionality of the transplanted tissue (1). A tissue-engineered adipose substitute that promotes tissue regeneration rather than repair would be of significant value to plastic surgeons in reconstructive and cosmetic applications. Such a substitute would provide a biocompatible scaffold that defines the appropriate three-dimensional tissue architecture and promotes host integration and implant vascularization. Ultimately, the scaffold should degrade as it is replaced by healthy host soft tissue. A number of different synthetic scaffolds have been investigated for adipose tissue engineering applications, including polyethylene glycol diacrylate (2), polyglycolic acid (3), polyethylene terephthalate (4), poly(lactic-co-glycolic acid) (5) and polytetrafluoroethylene (6). In addition, naturally-derived materials, such as collagen (7) and hyaluronic acid derivatives (8), Matrigel (9) and silk fibrin (10) have been studied for use in adipose tissue engineering. However, a number of problems have been observed with their application in soft tissue filling, such as absorption, poor cellular compatibility and foreign body reactions, which affect the widespread clinical application of these materials.

The extracellular matrix (ECM) is a complex network of macromolecules that provide an appropriate local microenvironment for the survival and activity of cells in vivo, and affect cellular shape, metabolism, function, migration, proliferation and differentiation $(11,12)$. ECM scaffolds have been prepared from the small intestine submucosalmatrix (13), blood vessels, skin (14-16), nerves (17), skeletal muscles (18) and bladder tissues (19), and ECM scaffolds derived from different tissues and organs have different components and ultrastructural properties (11). Adipose tissue represents a potentially abundant source of ECM, and previous studies have indicated that adipose tissue may represent an ideal scaffold material for the growth, differentiation and phenotypic maintenance of cells that have been harvested from adipose tissues $(20,21)$. However, the methods used to prepare 
adipose tissue ECM scaffolds have distinct effects upon the structural and functional components of the resultant scaffold material, and thus determine the functional effectiveness of the material in tissue engineering and regenerative medicine applications $(22,23)$. Flynn et al (21) prepared decellularized adipose tissues using physical and chemical treatments, including enzyme preparations; however, the prolonged time-periods required for chemical and enzyme treatments may affect the biocompatibility of materials. Choi et al (20) used high-speed centrifugation combined with chemical reagents, such as SDS, to achieve decellularization; however, this process was revealed to be cumbersome and lengthy.

The aim of the present study was to characterize the adipose ECM material derived using a distinct decellularization method, involving a series of successive physical (freezing, pressure and agitation) and chemical treatments (enzymatic digestion and immersion in polar solvents), that are commonly customized according to the tissue type. The authors of the present study focused on the removal of potential immunogenic components with the aim of using the resultant scaffold material for the purposes of allograft tissue engineering, and specifically evaluated the efficiency of cellular content removal, the effect on the scaffold ultrastructure, the retention of key ECM components and the ability of the resulting scaffold material to support the in vitro growth and differentiation of human adipose-derived stem cells (hASCs) toward an adipogenic lineage.

\section{Materials and methods}

Procurement of adipose tissues. Human adipose tissue was obtained from 8 healthy female donors (20-40 years old) who had undergone routine abdominoplasty at the Burns and Plastic Surgery Center of General Hospital of Lanzhou Military Command of the People's Liberation Army (Lanzhou, China) between October 2013 and January 2014. Written informed consent was obtained from all patients, and experiments were performed according to the Human Research Guidelines by the Institutional Review Board of General Hospital of Lanzhou Military Command of China. The samples were transported to the Clinical Laboratories of General Hospital of Lanzhou Military Command at room temperature (RT) within $30 \mathrm{~min}$.

Decellularization of adipose tissue. Conical tubes $(50 \mathrm{ml})$ containing the adipose tissue samples were submersed in liquid nitrogen for $10 \mathrm{~min}$ and then immediately placed in a $37^{\circ} \mathrm{C}$ water bath for $30 \mathrm{~min}$. This freeze-thaw cycle was repeated a further five times, before tissues were centrifuged at $1,800 \mathrm{xg}$ for $10 \mathrm{~min}$ at RT. Following removal of the fatty liquid portion, the tissues were subjected to a 12 -h polar solvent extraction using $99.9 \%$ isopropanol. The processed tissues were then rinsed in phosphate-buffered saline (PBS) three times for $30 \mathrm{~min}$ each time, and incubated in a solution of $0.05 \%$ trypsin, 0.05\% EDTA, $20 \mathrm{ng} / \mathrm{ml}$ DNAse I (Sigma-Aldrich; Merck KGaA, Darmstadt, Germany), and 20 ng/ml RNAse (Sigma-Aldrich; Merck KGaA) for $4 \mathrm{~h}$ with slow rotation at RT. Following four washes with PBS for $30 \mathrm{~min}$ each time, the tissues were incubated in $1 \%$ penicillin (Sigma-Aldrich; Merck $\mathrm{KGaA}$ ) and streptomycin (Sigma-Aldrich; Merck
$\mathrm{KGaA}$ ) for $12 \mathrm{~h}$ at $4^{\circ} \mathrm{C}$ and stored in sterile distilled water at $4^{\circ} \mathrm{C}$ until required.

Scanning electron microscopy (SEM). Decellularized adipose tissue samples were fixed in $2.5 \%$ glutaraldehyde for $1 \mathrm{~h}$ at RT. Following extensive rinsing with PBS, each sample was mounted onto a cover glass slide and air-dried at RT. The surface morphology of the ECM was observed by SEM (Hitachi S-4800 FE-SEM; Hitachi, Ltd., Tokyo, Japan) following coating with platinum at an accelerating voltage of $15 \mathrm{kV}$.

Evaluation of decellularization and delipidization. To determine the extent of decellularization of the adipose tissue, fresh and decellularized tissue samples were fixed in $10 \%$ neutral buffered formalin for $24 \mathrm{~h}$ at RT, rinsed with $70 \%$ ethanol, embedded in paraffin, and sectioned into 6-mm sections. Hematoxylin and eosin (H\&E) staining and Masson's trichrome staining were used to observe residual cells or cell fragments, and to characterize the collagen structure of the decellularized ECM. For H\&E staining, the tissue slices were deparaffinized and rinsed in anhydrous alcohol twice for $2 \mathrm{~min}$ and immersed in 95, 80 and 75\% alcohol for $1 \mathrm{~min}$ each before rinsing in PBS for $1 \mathrm{~min}$. After staining with hematoxylin for $5 \mathrm{~min}$ at $\mathrm{RT}$, the slices were rinsed in PBS and differentiated with $10 \mathrm{ml} / 1$ hydrochloric acid alcohol. Then they were incubated in eosin staining for $1 \mathrm{~min}$ at RT, rinsed with PBS for $30 \mathrm{sec}$, dehydrated in alcohol and observed under a CX31-12C04 light microscope (Olympus Corporation, Tokyo, Japan).

To elucidate changes in tissue components, a Masson trichrome staining kit (cat. no. 87019; Richard-Allan Scientific; Thermo Fisher Scientific, Inc., Waltham, MA, USA) was used according to the manufacturer's protocol. Stained tissue sections were imaged using bright field microscopy (Nikon EC600; Nikon Corporation, Tokyo, Japan).

Immunohistochemical staining was conducted to confirm the effectiveness of the cellular extraction process, as well as to characterize the distribution of the basement membrane components, including collagen type IV and laminin (LN). Sections of both fresh adipose tissue and decellularized adipose tissue were fixed with acetone and then treated with $3 \% \mathrm{H}_{2} \mathrm{O}_{2}$ in methanol for $30 \mathrm{~min}$ to block endogenous peroxidase activity. Samples were then stained with primary antibodies against collagen IV (ab21295; Abcam, Cambridge, MA, USA; 1:100 dilution) and laminin (ab11575; Abcam; 1:100 dilution) at $4^{\circ} \mathrm{C}$ overnight, and then washed four times with PBS (5 min/wash). HRP-labeled anti-rabbit secondary antibody (goat anti-rabbit IgG; A6154; Sigma-Aldrich; Merck KGaA) was added and the tissue was incubated at room temperature for $35 \mathrm{~min}$ before the secondary antibody was discarded. Tissue was washed four times with PBS (5 min/wash). DAB was added to detect the positive signal. Hematoxylin was added to stain the nucleus at room temperature for $1 \mathrm{~min}$, then after washing five times with PBS, neutral gum was used to close the slice. Finally the sections were observed under a light microscope.

Both native and decellularized tissue sections were deparaffinized, dehydrated using a graded ethanol series, and stained with DAPI at RT for 20 min (Thermo Fisher Scientific, Inc.) to identify nucleic acids. The stained sections were examined using a fluorescence microscope (IX81, Olympus Corporation). A light blue color indicated residual nucleic acids. 
DNA content was assessed using the DNeasy kit (Qiagen, Inc., Valencia, CA, USA). To achieve this, samples of lyophilized adipose matrix were weighed, and DNA was extracted according to the manufacturer's specifications (Qiagen, Inc.). The DNA content $(\mu \mathrm{g} / \mathrm{mg}$ dry weight ECM) was estimated from absorbance readings at $260 \mathrm{~nm}$ using a Synergy H4 microplate reader (BioTek Instruments, Inc., Winooski, VT, USA) and normalized to the initial dry weight of the sample.

Lipid removal from the tissue was assessed by staining with Oil red O dye (Sigma-Aldrich; Merck KGaA). The samples were fixed with $4 \%$ paraformaldehyde for $24 \mathrm{~h}$ and then dehydrated with ethanol and embedded in Leica JUNG tissue-freezing medium. The embedded tissue sections were then cut into $8 \mu \mathrm{m}$ sections. Oil Red $\mathrm{O}$ solution was added with a pipette and reacted for $7 \mathrm{~min}$ at RT. $1 \%$ hydrochloric acid was added to differentiate for $3 \mathrm{sec}$, then the sections were rinsed with distilled water for $5 \mathrm{sec}$ to terminate the differentiation. Sections were stained with hematoxylin for $1 \mathrm{~min}$, then rinsed in tap water for $2 \mathrm{~min}$, with gum arabic to seal and finally observed under a light microscope. Red colour indicated the presence of lipids.

Glycosaminoglycan $(G A G)$ content of prepared scaffolds. The concentration of GAG in decellularized adipose tissue samples was measured using the Blyscan Sulfated Glycosaminoglycan assay kit (Biocolor Ltd., Carrickfergus, UK). Samples were prepared by digestion of $50 \mathrm{mg} / \mathrm{ml}$ dry weight ECM in a solution containing $0.1 \mathrm{mg} / \mathrm{ml}$ proteinase $\mathrm{K}, 10 \mathrm{mM}$ Tris buffer (pH 8.0), $50 \mathrm{mM} \mathrm{NaCl}$ and $1 \mathrm{mM}$ EDTA for $24 \mathrm{~h}$ at $50^{\circ} \mathrm{C}$. GAG content was then assayed following the manufacturer's protocol (Biocolor, Ltd.). The absorbance was measured in a 96-well plate at $656 \mathrm{~nm}$ using a Synergy H4 microplate reader (BioTek Instruments, Inc.). Each assay was performed in duplicate, and one-way analysis of variance with Tukey's post hoc test was used to determine statistical significance.

Evaluation of mechanical properties. Tensile tests were conducted using a universal tensile machine (UTM) equipped with a 50-N load cell (H100K-S; Tinius Olsen Inc., Horsham, PA, USA). Tissue samples (15 $\mathrm{mm}$ in lengthx10 $\mathrm{mm}$ in width $0.15 \mathrm{~mm}$ in thickness) were pulled at a rate of $10 \mathrm{~mm} / \mathrm{min}$. Strain values were calculated by crosshead displacement, and stress values were calculated by dividing the measured force by the cross-sectional area of the sample. A total of 5 specimens were measured, and the data was averaged. True stress $(\sigma)$ and true strain $(\varepsilon)$ were calculated using the following formulas: $\sigma=\mathrm{F} / \mathrm{A}$, where $\mathrm{F}$ is the force and $\mathrm{A}$ is the cross-sectional area of the tissue strip. Because the tissue undergoes pronounced deformation during testing, the cross-sectional area decreases as the strip is stretched. Thus, the cross-sectional area can be calculated as $\mathrm{A}=\mathrm{LWH} /(\mathrm{L}+\Delta \mathrm{L})$, where $\mathrm{W}$ is the width of the tissue, $\mathrm{H}$ is the thickness, and $\Delta \mathrm{L}$ is the elongation. Strain $(\varepsilon)$ is defined as $\varepsilon=\Delta \mathrm{L} / \mathrm{L}$. Because the Young's modulus (E) at any point of the curve is equal to the value of the slope, it can be obtained by $\mathrm{E}=\mathrm{d} \sigma / \mathrm{d} \varepsilon$.

In order to assess swelling behavior, each dried sample was incubated in $5 \mathrm{ml} \mathrm{PBS}$ at $37^{\circ} \mathrm{C}$ for up to 14 days. At different time points (1, $24 \mathrm{~h}$ and 3, 7, 10 and 14 days), samples were removed, and the wet weight $\left(\mathrm{W}_{\mathrm{w}}\right)$ was determined. Scaffolds were then dried in a vacuum oven at $37^{\circ} \mathrm{C}$ until a constant mass was reached $\left(\mathrm{W}_{\mathrm{d}}\right)$, and sample swelling ratios were calculated using the following formula: Swelling ratio $=\left(\mathrm{W}_{\mathrm{w}}-\mathrm{W}_{\mathrm{d}}\right) / \mathrm{W}_{\mathrm{d}}$.

The porosity of the prepared scaffolds was estimated through liquid displacement. Each sample was immersed in $5 \mathrm{ml}$ deionized water for $4 \mathrm{~h}$ at RT, and the change in the fluid volume was recorded prior to (DV1) and following (DV2) immersion of the scaffold samples. The porosity was estimated using the following formula: Porosity $(\%)=($ DV1-DV2)/DV1 x 100.

In order to determine the biodegradability of scaffolds, acellular ECM samples were weighed and incubated in PBS containing 0.05 and $0.2 \%$ collagenase $\mathrm{I}$ at $37^{\circ} \mathrm{C}$. At predetermined time intervals $(4,12,24,36,48$ and $72 \mathrm{~h})$, the samples were removed, rinsed with distilled water, dried under vacuum and weighed. The biodegradability was calculated using the following equation: Degradation $(\%)=100 \times\left(\mathrm{W}_{0}-\mathrm{W}_{\mathrm{t}}\right) / \mathrm{W}_{0}$, where $\mathrm{W}_{0}$ represents the initial weight and $\mathrm{W}_{\mathrm{t}}$ represents the weight following a specific time-interval, $t$. The results are presented as the mean \pm standard deviation $(n=5)$.

Human adipose-derived stem cell (hASC) culture on adipose-derived ECM material. hASCs were isolated from the subcutaneous adipose tissue of 3 healthy female donors (20-40 years old) that had undergone liposuction at Lanzhou General Hospital (Lanzhou, China) between October 2013 and January 2014. According to the modified procedure for the isolation of hASCs (24), the adipose tissues were washed with PBS containing 5\% penicillin/streptomycin (Gibco; Thermo Fisher Scientific, Inc.). The tissues were then digested in PBS supplemented with $0.01 \%$ (w/v) collagenase type II (Gibco; Thermo Fisher Scientific, Inc.) for $1 \mathrm{~h}$ at $37^{\circ} \mathrm{C}$. The digested tissues were filtered through a $100-\mu \mathrm{m}$ mesh to remove aggregated tissue and debris. The filtered suspension was centrifuged at $200 \mathrm{x}$ g for $7 \mathrm{~min}$, and the pellet was washed several times with PBS. The isolated cells were incubated in Dulbecco's modified Eagle's medium (DMEM; Gibco; Thermo Fisher Scientific, Inc.) supplemented with $10 \%$ fetal bovine serum (Gibco; Thermo Fisher Scientific, Inc.) and 1\% penicillin-streptomycin at $37^{\circ} \mathrm{C}$ in $5 \% \mathrm{CO}_{2}$.

The ECM scaffolds were sterilized by ethylene oxide gas $(800 \mathrm{mg} / \mathrm{l})$, washed with PBS and incubated at $37^{\circ} \mathrm{C}$ and $5 \%$ $\mathrm{CO}_{2}$ overnight in growth medium prior to seeding. Each scaffold was then transferred to a 24-well cell culture dish and seeded with $1 \times 10^{6} \mathrm{hASC}$ (at passage 2) $/ 100 \mathrm{~mm}^{2}$ in complete growth medium. The medium was refreshed every 2-3 days. Following $24 \mathrm{~h}$ in culture, an MTT assay was used to measure the viability of hASCs in triplicate samples for 14 consecutive days. hASCs that were not incubated with scaffolds were used as controls. Briefly, at predetermined time intervals (every day), $0.4 \mathrm{ml} \mathrm{MTT} \mathrm{solution}(5 \mathrm{mg} / \mathrm{ml}$ ) was injected into the hydrogel and incubated for $4 \mathrm{~h}$. Thereafter, $4 \mathrm{ml}$ DMSO was added into each well and allowed to react until dissolution of the formazan pigment. Afterwards, $200 \mu \mathrm{l}$ of the pigment solution of each sample was transferred to a new 96-well plate, and the absorbance was measured at $570 \mathrm{~nm}$. In addition, cell viability analysis was performed using a commercially available Live/Dead ${ }^{\circledR}$ Viability/Cytotoxicity kit (Invitrogen; Thermo Fisher Scientific, Inc.). The cell-seeded adipose ECM scaffolds were washed twice with PBS and then incubated for $10 \mathrm{~min}$ in a $1: 1$ mixture of $0.01 \mathrm{mg} / \mathrm{ml}$ propidium-iodide (PI) 
A

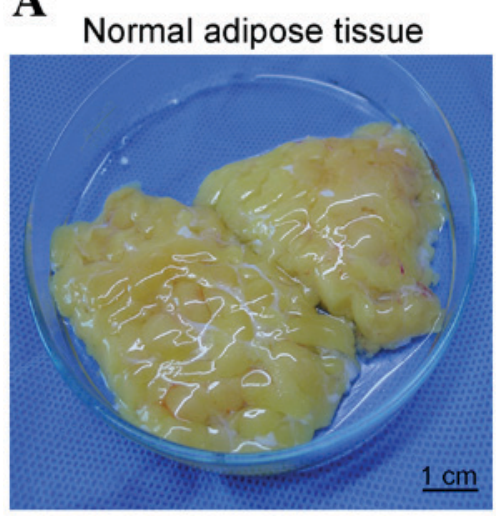

B

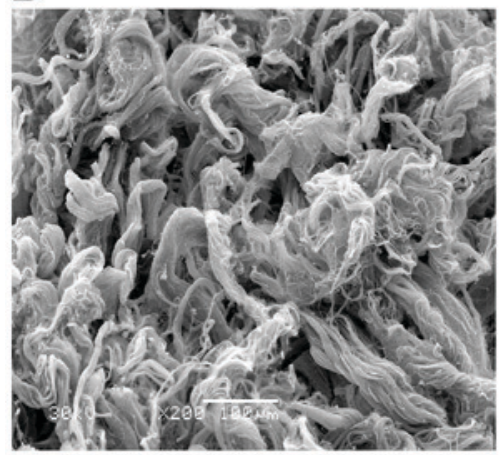

Adipose tissue-derived ECM scaffolds
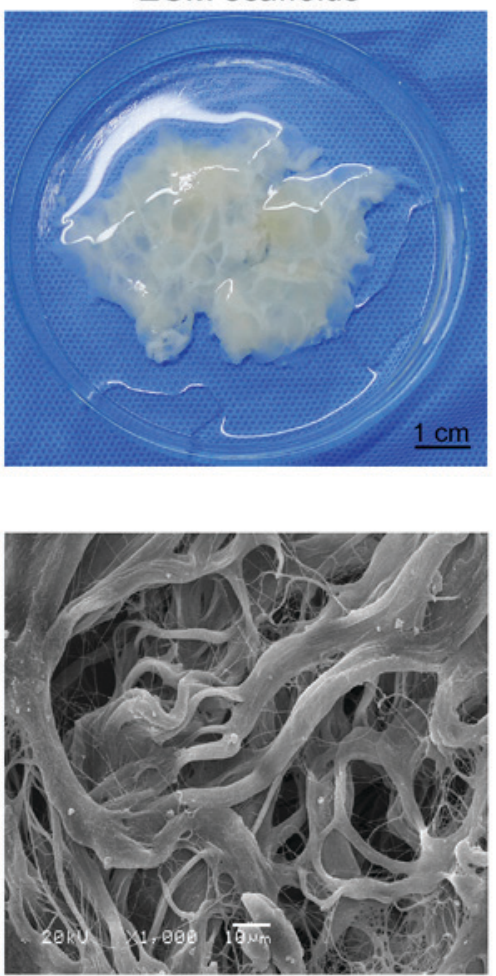

Figure 1. (A) Macroscopic images of a human fresh adipose tissue and human adipose tissue-derived ECM scaffolds (scale bar, $1 \mathrm{~cm}$ ). (B) Scanning electron microscopy images of the ECM scaffolds demonstrating the network structure of collagen fibers and the range of pore sizes (left panel, magnification, 200 , scale bar, $100 \mu \mathrm{m}$; right panel, magnification, $\mathrm{x} 1,000$, scale bar, $10 \mu \mathrm{m})$. ECM, extracellular matrix.

and $5 \mathrm{mg} / \mathrm{ml}$ fluorescein diacetate (FDA). Seeded materials were then imaged using a confocal microscope (Olympus Fluoview 1000MP, Olympus Corporation). Images were taken at sequential planes and flattened into one single plane using Metamorph software 7.7 (Molecular Devices, LLC, Sunnyvale, CA, USA). Five different representative low power fields were taken from each sample, and signal densities from PI and FDA were measured with Metamorph software and used to determine the percentages of live and dead cells within the materials. Cell morphology was visualized using SEM using the aforementioned methods. Collagen type I scaffolds (Sigma-Aldrich; Merck KGaA) were used according to the manufacturer's instructions as a control substrate for hASC growth.

Induction of adipogenic differentiation. At $48 \mathrm{~h}$ following the seeding of hASCs on ECM scaffolds, serum-free adipogenic differentiation medium (serum-free DMEM, Ham's F-12 supplemented with $15 \mathrm{mM} \mathrm{NaHCO}$, 15 mM HEPES, $33 \mathrm{mM}$ biotin, $17 \mathrm{mM}$ pantothenate, $10 \mathrm{mg} / \mathrm{ml}$ transferrin, $100 \mathrm{nM}$ cortisol, $66 \mathrm{nM}$ insulin, $1 \mathrm{nM}$ tri-iodothyronine, $100 \mathrm{U} / \mathrm{ml}$ penicillin and $0.1 \mathrm{mg} / \mathrm{ml}$ streptomycin) was added to hASCs to induce adipogenic differentiation. Oil Red $\mathrm{O}$ staining was performed to characterize intracellular lipid accumulation in the hASCs following 14 days. To quantitatively assess the adipogenic response, glycerol-3-phosphate dehydrogenase (GPDH) enzyme activity levels were measured following 72 h, 7 and 14 days, using a GPDH Activity Measurement kit (cat. no. KT-010; Kamiya Biomedical Company, Seattle,
WA, USA; $n=3$ per group) according to the manufacturer's protocol. Differentiated (positive control) and undifferentiated (negative control) hASCs were seeded in 24-well plates at $1 \times 10^{6}$ cells/well in $5 \mathrm{ml}$ of complete growth medium. Within each sample, the absorbance $(340 \mathrm{~nm})$ was measured over a 10 -min period at $25^{\circ} \mathrm{C}$ using a microplate reader. The results were normalized to the total intracellular protein content as determined using the Bio-Rad Protein assay kit (Bio-Rad Laboratories, Inc., Hercules, CA, USA). For GPDH activity, 1 unit (U) was defined as the level of activity required to oxidize $1 \mathrm{mmol} \mathrm{NADH}$ in $1 \mathrm{~min}$.

Statistical analysis. Data are expressed as the mean \pm standard deviation, and statistical analyses were performed using one-way analysis of variance with Tukey's post hoc comparison of the means. The SPSS 13.0 software program (SPSS, Inc., Chicago, IL, USA) was used to perform statistical tests. $\mathrm{P}<0.05$ was considered to indicate a statistically significant difference.

\section{Results}

Generation and characterization of adipose tissue-derived ECM scaffolds. The hydrated mass of decellularized ECM exhibited a white, shiny and stretchable appearance, and typically represented between $30-40 \%$ of the original tissue mass (Fig. 1A). Following freeze-drying, the material appeared as a soft porous sponge with a well-defined three-dimensional architecture, as observed in SEM images (Fig. 1B). The 


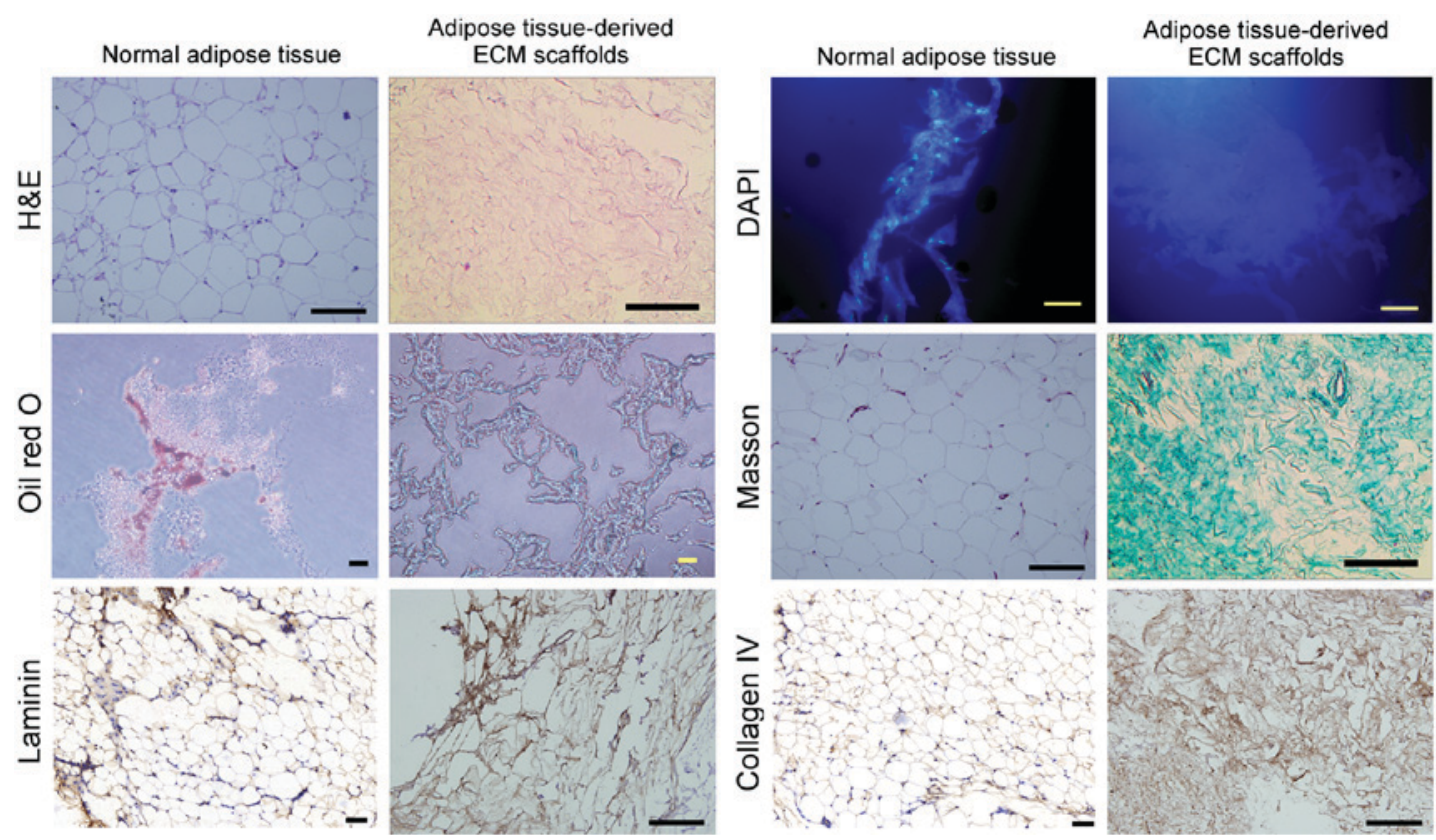

Figure 2. Histological analysis of normal human adipose tissue samples and human adipose tissue-derived ECM scaffolds by (scale bars, $50 \mu \mathrm{m}$ ). Cell components were visualized by staining with H\&E and DAPI. Lipid content was assessed using Oil red O staining. Masson's trichrome staining was employed to characterize the collagen structure of the decellularized ECM. Immunohistochemical analysis was used to characterize the distribution of the laminin and collagen IV. ECM, extracellular matrix; H\&E, hematoxylin and eosin.

network structure of these scaffolds was composed primarily of collagen fibers of different diameters. The scaffold pore sizes ranged from 20-200 $\mu \mathrm{m}$, and sections of the fibers were not continuous (Fig. 1B). The scaffolds displayed uneven and smooth surfaces with an extensive surface area, which may be favorable for cell adhesion and proliferation. No intact nuclei were observed in tissue sections stained with $\mathrm{H} \& \mathrm{E}$ or labeled with DAPI (Fig. 2). Oil red O staining demonstrated a complete absence of lipids in adipose tissue-derived ECM scaffolds (Fig. 2).

Composition of adipose tissue-derived ECM scaffolds. Masson's trichrome staining demonstrated that the primary component of the ECM scaffolds following decellularization was collagen fibers, and no additional cellular structures were identified (Fig. 2). Immunohistochemical staining demonstrated that LN and collagen type IV remained abundant in the decellularized matrix (Fig. 2). The total DNA content was $<50 \mathrm{ng}$ double-stranded DNA/mg of scaffold dry weight (Fig. 3A). GAG analysis estimated an average of $39.67 \pm 2.31 \mu \mathrm{g}$ sulfated GAG/g dry adipose ECM, and 42.15 $\pm 4.36 \mu \mathrm{g}$ sulfated GAG/g normal adipose tissue (Fig. 3B).

Mechanical properties of adipose tissue-derived ECM scaffolds. The mechanical properties of the decellularized samples were investigated using an UTM, and a typical stress-strain curve is shown in Fig. 3C. The initial tensile strength and Young's modulus were $0.22 \pm 0.05$ and $65.70 \pm 5.97 \mathrm{MPa}$ (at $0.1 \%$ of initial strain), respectively (Fig. 3C). The maximum elongation at the point of breakage was $65.02 \pm 8.26 \%$ of the initial length (data not shown). The ECM scaffolds swelled in time-dependent manner until $168 \mathrm{~h}$, and the maximum PBS uptake ratio was $561 \pm 19.3 \%$ at this time point (Fig. 3D), which indicates that the scaffold absorbed $\sim 6$ times its own weight of medium. By determining liquid displacement measurements, the ECM scaffolds exhibited a porosity of $90.43 \pm 6.5 \%$ (mean \pm standard error, $n=5$; data not shown), which may facilitate cellular penetration and proliferation.

The ECM scaffolds demonstrated sustained degradation in the presence of collagenase, and the degradation rate significantly increased with increasing collagenase concentration $(\mathrm{P}<0.05$; Fig. 3E). The scaffolds exhibited rapid degradation $(>50 \%)$ within the first $24 \mathrm{~h}$, and complete degradation within 3 days of incubation in PBS containing $0.2 \%$ collagenase at $37^{\circ} \mathrm{C}$ (Fig. 3E).

In vitro cell viability and adipogenic differentiation. The levels of hASC adhesion and viability on ECM scaffolds were compared to those observed on collagen type I scaffolds by MTT assay analysis. As demonstrated in Fig. 4A, the mean optical density value for hASCs on the ECM scaffolds at day 1 was slightly lower than that observed on the collagen type I scaffolds. However, the viability of hASCs on ECM scaffolds increased at a slightly faster rate when compared with collagen type I scaffolds following 1 week (Fig. 4A). The mean optical density value for cells cultured on the ECM scaffolds increased with time in culture, and was significantly higher when compared with cells cultured on the collagen type I scaffolds at day 14 ( $\mathrm{P}<0.05$; Fig. 4A). These results suggest that the adipose tissue-derived ECM scaffold promoted the adhesion and growth of hASCs.

Representative images of cellular organization at $72 \mathrm{~h}$ and 7 days post-cell seeding are shown in Fig. 4B. Staining of cells with a Live/Dead ${ }^{\circledR}$ Viability/Cytotoxicity kit revealed that the majority of cells were viable when cultured on ECM and collagen type I scaffolds for $72 \mathrm{~h}$ (Fig. 4B). However, following 7 days, a greater number of dead cells were observed on the collagen type I scaffolds when compared with the adipose 

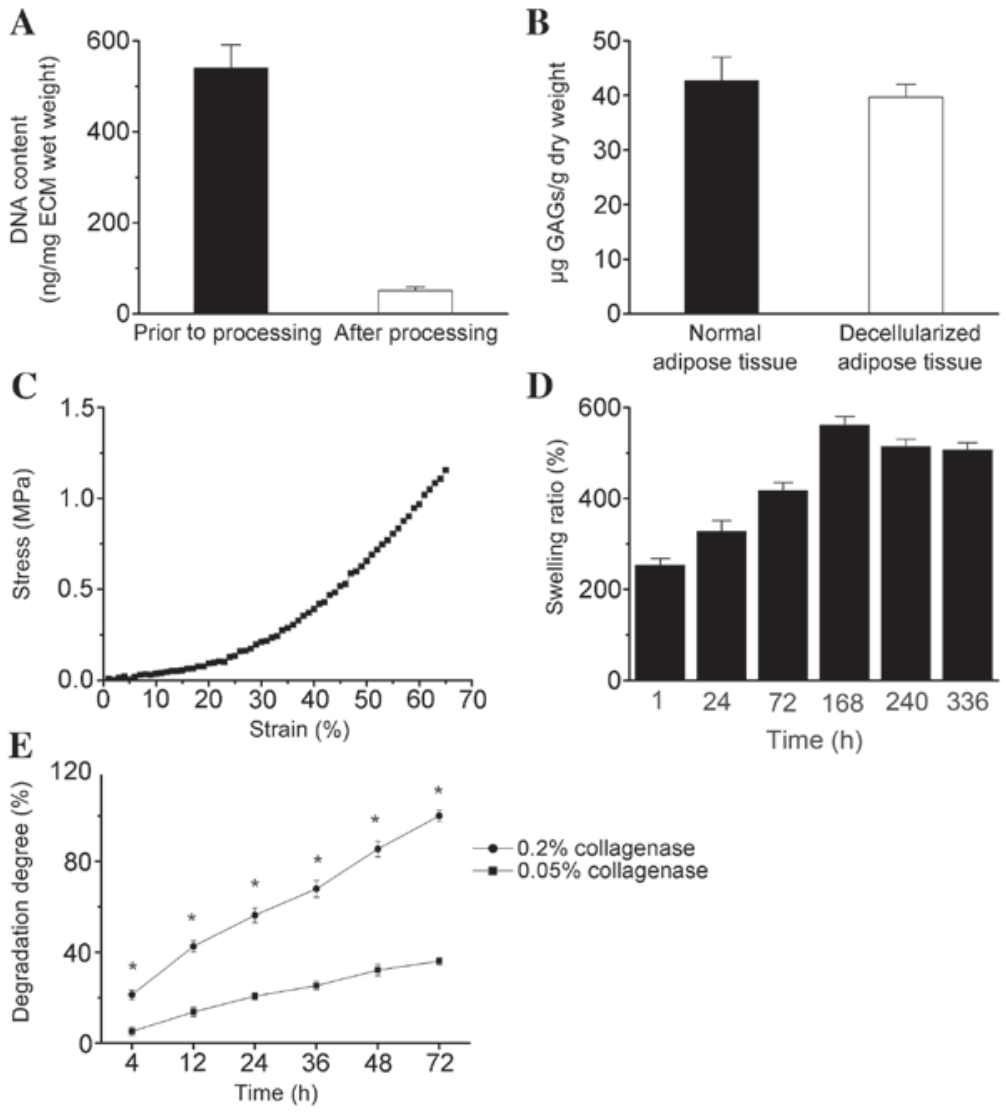

Figure 3. Biochemical analysis of (A) residual DNA and (B) sulfated GAG content in adipose tissue-derived ECM scaffolds. (C) A representative stress-strain curve, (D) swelling ratio (E) and degradation profile of ECM scaffolds. Data were normalized to the dry weight of ECM, except for DNA content and stress-strain analysis. Data are presented as the mean \pm standard deviation. ${ }^{*} \mathrm{P}<0.05$ vs. $0.05 \%$ collagenase. GAG, glycosaminoglycan; ECM, extracellular matrix.

tissue-derived ECM scaffolds, and a higher number of viable cells were attached to the ECM scaffolds (Fig. 4B). These results indicated that the ECM scaffolds promoted hASC adhesion and growth. SEM analysis revealed that hASCs cultured on the ECM scaffolds exhibited good dispersal and distribution patterns on the scaffold surface area (Fig. 4C). During the first 1-3 days, hASCs exhibited a spherical morphology, whereas they progressively dispersed and displayed extended pseudopodia by 5-7 days, potentially due to cell proliferation (Fig. 4C). A representative Oil Red $\mathrm{O}$ staining image obtained following 14 days of hASC differentiation on adipose tissue-derived ECM scaffolds is presented in Fig. 4D, demonstrating that lipid loading was detected in hASCs.

The average GPDH activity levels in hASCs cultured on the two scaffold types are presented in Fig. 5. At 3 days following induction of differentiation, GPDH activity levels in hASCs cultured on the adipose tissue-derived ECM scaffolds $(4.18 \pm 2.25 \mathrm{mU} / \mathrm{mg} ; \alpha=0.018, \mathrm{P}<0.05)$ and collagen type I scaffolds $(4.32 \pm 1.89 \mathrm{mU} / \mathrm{mg} ; \alpha=0.014, \mathrm{P}<0.05)$, as well as in the induced positive control cells $(4.61 \pm 2.53 \mathrm{mU} / \mathrm{mg} ; \alpha=0.009$, $\mathrm{P}<0.05)$ were significantly higher when compared with the non-induced negative control cells $(1.33 \pm 0.11 \mathrm{mU} / \mathrm{mg})$. However, no statistically significant differences were observed among the GPDH activity levels in the former three groups following 3 days. GPDH activity levels in the ECM scaffold, collagen type I scaffold and induced positive control groups were greater at 7 days following induction of differentiation when compared with 3 days (Fig. 5). However, at this time point, the GPDH activity levels of hASCs on the ECM scaffolds $(14.7 \pm 3.56 \mathrm{mU} / \mathrm{mg} ; \alpha=0.001, \mathrm{P}<0.05)$ and collagen type I scaffolds $(13.5 \pm 3.14 \mathrm{mU} / \mathrm{mg} ; \alpha=0.004, \mathrm{P}<0.05)$ were significantly greater than those of the induced positive control cells $(7.83 \pm 3.12 \mathrm{mU} / \mathrm{mg})$ and non-induced negative control cells $(1.28 \pm 0.09 \mathrm{mU} / \mathrm{mg})$. No significant difference in GPDH activity in hASCs cultured on the ECM scaffolds and collagen type I scaffolds was observed at 7 days. At 14 days following induction of differentiation, although the GPDH activity of hASCs cultured on the collagen type I scaffolds $(21.7 \pm 9.45 \mathrm{mU} / \mathrm{mg})$ was significantly higher than that of the induced positive control cells $(9.86 \pm 4.26 \mathrm{mU} / \mathrm{mg} ; \alpha=0, \mathrm{P}<0.05)$ and the non-induced negative control cells $(0.75 \pm 0.13 \mathrm{mU} / \mathrm{mg} ; \alpha=0.001, \mathrm{P}<0.05)$, GPDH activity in hASCs cultured on the ECM scaffolds (27.4 $\pm 7.82 \mathrm{mU} / \mathrm{mg} ; \alpha=0.001, \mathrm{P}<0.05)$ was significantly greater compared with hASCs cultured on collagen type I scaffolds (Fig. 5). As expected, low GPDH activity levels were observed for the non-induced control samples at all time points. Notably, GPDH activity in hASCs increased by $>6$-fold on the ECM scaffolds from $3(4.18 \pm 2.25 \mathrm{mU} / \mathrm{mg})$ to 14 days (27.4 $\pm 7.82 \mathrm{mU} / \mathrm{mg})$.

\section{Discussion}

Decellularized tissues derived from the aorta, heart valve, pericardium and tendons of human and animal cadavers have 

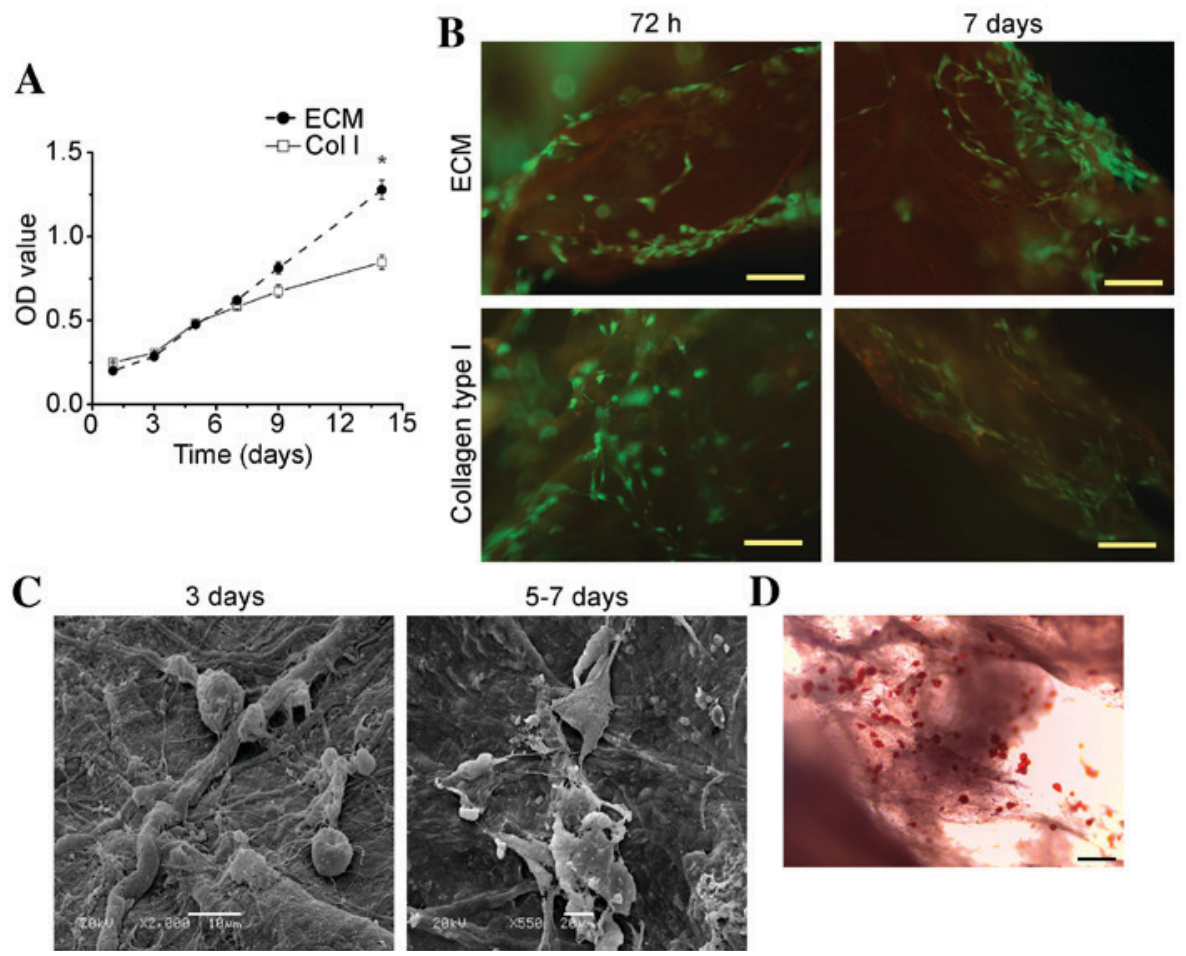

\begin{abstract}
5-7 days
\end{abstract}
D
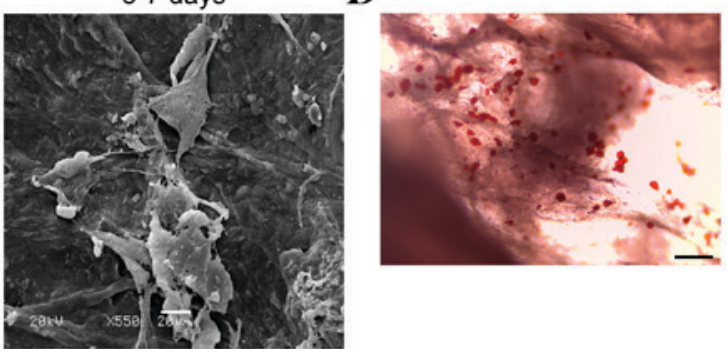

Figure 4. hASC culture on adipose tissue-derived ECM scaffolds in vitro. (A) The growth of hASCs on ECM or Col I scaffolds, as determined using MTT assays. Data are presented as the mean \pm standard deviation. ${ }^{~} \mathrm{P}<0.05$ vs. Col I. (B) Analysis of hASC viability at $72 \mathrm{~h}$ and 7 days following culture on ECM scaffolds and collagen type I scaffolds, as determined using a Live/Dead ${ }^{\circledR}$ Viability/Cytotoxicity kit. Green fluorescence indicates live cells, and red fluorescence indicates dead cells (magnification, x100; scale bar, $50 \mu \mathrm{m}$ ). (C) Scanning electron microscopy images showing the adherence of hASCs to ECM scaffolds during the first 3 days in culture (magnification, x2,000; scale bar, $10 \mu \mathrm{m}$ ) and hASC dispersal and extension of pseudopodia following 5-7 days (magnification, x550; scale bar, $20 \mu \mathrm{m}$ ). (D) Representative optical microscopy image of Oil Red O staining for intracellular lipid accumulation within hASCs cultured on ECM scaffolds at 14 days following induction of adipogenic differentiation (magnification, x100; scale bar, $50 \mu$ m). hASC, human adipose-derived stem cell; ECM, extracellular matrix; OD, optical density; Col I, collagen type 1 scaffolds.

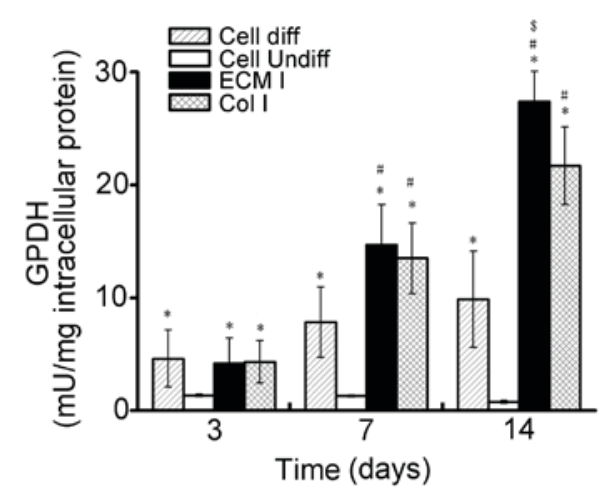

Figure 5. GPDH activity levels (mU/mg total intracellular protein), as determined using a spectrophotometric assay (absorbance measured at $340 \mathrm{~nm})$. GPDH activity levels were measured in samples at 3,7 and 14 days following induction of adipogenic differentiation ( $\mathrm{n}=3 /$ group). Data are presented as mean \pm standard deviation. ${ }^{*} \mathrm{P}<0.05$ vs. Cell undiff; " $\mathrm{P}<0.05$ vs. Cell diff and ${ }^{\mathrm{S}} \mathrm{P}<0.05$ vs. Col I. GPDH, glycerol-3-phosphate dehydrogenase; ECM, extracellular matrix; Col I, collagen type 1 scaffolds; diff/undiff, differentiated/undifferentiated.

been developed and investigated for clinical application in humans (25-28). Adipose tissue contains multiple cell types, including adipocytes, fibroblasts, smooth muscle cells, endothelial cells, immune cells and ASCs (29). Therefore, adipose tissue is a rich source of ECM components, such as type I, II and IV collagens. In addition, adipose tissue is a major endocrine and secretory organ that releases a wide variety of cytokines (20). Substantial quantities of adipose tissue obtained during clinical liposuction and abdominoplasty procedures are discarded as medical waste. The ability to obtain cells and scaffold materials from human adipose tissue was a key factor for the authors' approach to employ this tissue type as a source for a decellularized ECM scaffold in the present study, and this approach may be considered for autologous tissue engineering.

The aim of decellularization is to remove immunogenic cellular components from the tissue structure, while maintaining the biological activity and mechanical integrity of the ECM network. Different methods for decellularization, involving physical, chemical and enzymatic treatments, have been widely studied (30). Generally, the use of any of these treatment methods alone is insufficient to achieve complete decellularization, and combinations of these treatments have been demonstrated to increase the decellularization efficiency and optimize the tissue texture $(31,32)$. Previous studies involving the decellularization of tissues or organs have used SDS more extensively than any other chemical reagent. However, the decellularization protocol presented by Flynn et al (21) was designed to avoid the use SDS, as this reagent has been demonstrated to alter the matrix architecture and affect cellular repopulation of the matrix. Although 99.9\% isopropanol has been demonstrated to be effective for the decellularization of adipose tissues within $48 \mathrm{~h}(21)$, the results of the present study indicated that complete decellularization 
of adipose tissue was possible following $12 \mathrm{~h}$ of $99.9 \%$ isopropanol extraction and enzymatic digestion in combination with repeated freeze-thaw treatments. Based on previous experience, human adipose tissue is a loose connective tissue that is easily disrupted by repeated freeze-thaw cycles, and the addition of strong chemical and enzymatic agents is necessary to facilitate the removal of cellular components. A shorter processing time, as demonstrated in the current study, may be very beneficial in terms of the cost and scalability of this approach for clinical use. Histologic and SEM analyses indicated that the finalized protocol applied in the current study was highly effective at removing the cellular components from adipose tissue, while minimizing macroscopic alterations to the ECM network in the shortest processing time-frame.

Biochemical studies performed in the present study indicated that the decellularized adipose tissue retained a complex composition of proteins, peptides and GAGs. Sulfated GAGs are known for their ability to sequester growth factors and subsequently present them to cells $(33,34)$. Therefore, their presence within the matrix provides a possible avenue for bioactive molecule delivery in vitro and in vivo. Immunochemical staining revealed the preservation of collagen fibers, a major component of native adipose ECM. Collagen type IV, which is a fibrillar collagen, contains various binding sites for bioactive molecules that modulate cellular behavior and therefore not only functions as a structural protein (35). In the present study, LN was detected in decellularized adipose ECM tissues, despite exhibiting a slight reduction when compared with native tissues. LN promotes the attachment of epithelial cells to the basal lamina, and is involved in the migration and growth of these cells (16). Therefore, retention of these adhesion molecules within ECM scaffolds following chemically-induced cell extraction may promote the migration and growth of cells in these scaffolds during repopulation in vivo or in vitro.

In the present study, mechanical testing of the ECM scaffolds indicated that they maintained a mechanical strength comparable to that of the native tissue. This suggests that the applied decellularization process preserved the ECM scaffold structure. The average porosity of the acellular ECM scaffolds was $90.43 \%$, which is sufficient for cell infiltration, oxygen transport, and nutrient and waste exchange (36). Finally, the median pore sizes within the ECM scaffolds ranged from 20-200 $\mu \mathrm{m}$, which are appropriate for the adhesion of many types of cells (37).

The results of the present study demonstrated that hASCs cultured on the human adipose tissue-derived ECM scaffolds exhibited satisfactory adhesion and viability in vitro. In addition, the surface features and chemical and biological compositions of human adipose tissue-derived ECM scaffolds were highly supportive of three-dimensional stem cell culture. SEM analysis indicated that the cells exhibited a star-shaped morphology upon adhesion to the ECM scaffolds, which was distinct from their original spherical morphology. The results suggest that the prepared ECM scaffolds provided sufficient space to support the growth and proliferation of hASCs.

In subsequent in vitro experiments investigating hASC adipogenesis, the adipose tissue-derived ECM scaffolds were observed to strongly support adipogenesis of these cells. Oil red $\mathrm{O}$ staining revealed that the hASCs differentiated into adipose cells on the ECM scaffolds, as they contained a large quantity of lipid droplets. In addition, the observed levels of GPDH enzyme activity provided additional evidence that the ECM scaffolds were adipo-inductive $(21,38)$. At 14 days following induction of differentiation, the GPDH activity in cells cultured on the ECM scaffolds was significantly higher when compared with cells cultured on collagen type I scaffolds. These results clearly demonstrated that the ECM composition and scaffold architecture serve critical roles in directing the cellular response, which supports the tissue-specific approach for adipose regeneration.

In conclusion, the results of the present study demonstrated that human adipose tissue may be successfully decellularized through treatment with repeated freeze-thaw cycles, centrifugation, polar solvent extraction and enzymatic digestion. The decellularized ECM samples exhibited high pore interconnectivity and mechanical properties for adequate use as tissue engineering scaffolds. hASCs were observed to adhere, spread, proliferate and differentiate into adipocytes on the ECM scaffolds. Ultimately, the results of the present study indicated that decellularized adipose tissue-derived ECM prepared using the described method, presents a promising substrate for the repair of various defective or damaged human tissues.

\section{Acknowledgements}

This study was supported by grants from the National Natural Science Foundation of China (grant no. 81401612) and the Key Project of the '12th Five-Year Plan' for Medical Science and Technology of PLA (grant no. BWS11C061).

\section{References}

1. Wu LC, Bajaj A, Chang DW and Chevray PM: Comparison of donor-site morbidity of SIEA, DIEP, and muscle-sparing TRAM flaps for breast reconstruction. Plast Reconstr Surg 122: 702-709, 2008.

2. Alhadlaq A, Tang M and Mao JJ: Engineered adipose tissue from human mesenchymal stem cells maintains predefined shape and dimension: Implications in soft tissue augmentation and reconstruction. Tissue Eng 11: 556-66, 2005.

3. Fischbach C, Spruss T, Weiser B, Neubauer M, Becker C, Hacker M, Göpferich A and Blunk T: Generation of mature fat pads in vitro and in vivo utilizing 3-D long-term culture of 3T3-L1 preadipocytes. Exp Cell Res 300: 54-64, 2004.

4. Kang X, Xie Y and Kniss DA: Adipose tissue model using three-dimensional cultivation of preadipocytes seeded onto fibrous polymer scaffolds. Tissue Eng 11: 458-468, 2005.

5. Patrick CW Jr, Zheng B, Johnston C and Reece GP: Long-term implantation of preadipocyte-seeded PLGA scaffolds. Tissue Eng 8: 283-293, 2002.

6. Kral JG and Crandall DL: Development of a human adipocyte synthetic polymer scaffold. Plast Reconstr Surg 104: 1732-1738, 1999.

7. Gentleman E, Nauman EA, Livesay GA and Dee KC: Collagen composite biomaterials resist contraction while allowing development of adipocytic soft tissue in vitro. Tissue Eng 12: 1639-1649, 2006.

8. Halbleib M, Skurk T, de Luca C, von Heimburg D and Hauner H: Tissue engineering of white adipose tissue using hyaluronic acid-based scaffolds. I: In vitro differentiation of human adipocyte precursor cells on scaffolds. Biomaterials 24: 3125-3132, 2003.

9. Kawaguchi N, Toriyama K, Nicodemou-Lena E, Inou K, Torii S and Kitagawa Y: De novo adipogenesis in mice at the site of injection of basement membrane and basic fibroblast growth factor. Proc Natl Acad Sci USA 95: 1062-1066, 1998. 
10. Mauney JR, Nguyen T, Gillen K, Kirker-Head C, Gimble JM and Kaplan D: Engineering adipose-like tissue in vitro and in vivo utilizing human bone marrow and adipose-derived mesenchymal stem cells with silk fibroin 3D scaffolds. Biomaterials 28: 5280-5290, 2007.

11. Badylak SF, Freytes DO and Gilbert TW: Extracellular matrix as a biological scaffold material: Structure and function. Acta Biomater 5: 1-13, 2009.

12. Jin CZ, Choi BH, Park SR and Min BH: Cartilage engineering using cell-derived extracellular matrix scaffold in vitro. J Biomed Mater Res A 92: 1567-1577, 2010.

13. Keskin M, Kelly CP, Moreira-Gonzalez A, Lobocki C, Yarim M, Kaplan S and Jackson IT: Repairing critical-sized rat calvarial defects with a periosteal cell-seeded small intestinal submucosal layer. Plast Reconstr Surg 122: 400-409, 2008.

14. Uflacker AB and Janis JE: The use of acellular dermal matrix in the correction of visible parasternal deformities after breast reconstruction. Plast Reconstr Surg 126: 34e-36e, 2010.

15. Altman AM, Chiu ES, Bai X, Yan Y, Song YH, Newsome RE and Alt EU: Human adipose-derived stem cells adhere to acellular dermal matrix. Aesthetic Plast Surg 32: 698-699, 2008.

16. Atkinson JJ, Adair-Kirk TL, Kelley DG, Demello D and Senior RM: Clara cell adhesion and migration to extracellular matrix. Respir Res 9: 1, 2008.

17. Hudson TW, Liu SY and Schmidt CE: Engineering an improved acellular nerve graft via optimized chemical processing. Tissue Eng 10: 1346-1358, 2004.

18. Borschel GH, Dennis RG and Kuzon WM Jr: Contractile skeletal muscle tissue-engineered on an acellular scaffold. Plast Reconstr Surg 113: 595-604, 2004

19. Gilbert TW, Stolz DB, Biancaniello F, Simmons-Byrd A and Badylak SF: Production and characterization of ECM powder: Implications for tissue engineering applications. Biomaterials 26 : 1431-1435, 2005

20. Choi JS, Yang HJ, Kim BS, Kim JD, Lee SH, Lee EK, Park K, Cho YW and Lee HY: Fabrication of porous extracellular matrix scaffolds from human adipose tissue. Tissue Eng Part C Methods 16: 387-396, 2010.

21. Flynn LE: The use of decellularized adipose tissue to provide an inductive microenvironment for the adipogenic differentiation of human adipose-derived stem cells. Biomaterials 31: 4715-4724, 2010.

22. Brown BN, Freund JM, Han L, Rubin JP, Reing JE, Jeffries EM, Wolf MT, Tottey S, Barnes CA, Ratner BD and Badylak SF: Comparison of three methods for the derivation of a biologic scaffold composed of adipose tissue extracellular matrix. Tissue Eng Part C Methods 17: 411-421, 2011.

23. Wu I, Nahas Z, Kimmerling KA, Rosson GD and Elisseeff JH: An injectable adipose matrix for soft-tissue reconstruction. Plast Reconstr Surg 129: 1247-1257, 2012

24. Bunnell BA, Flaat M, Gagliardi C, Patel B and Ripoll C: Adipose-derived stem cells: Isolation, expansion and differentiation. Methods 45: 115-120, 2008.

25. De Cock LJ, De Koker S, De Vos F, Vervaet C, Remon JP and De Geest BG: Layer-by-layer incorporation of growth factors in decellularized aortic heart valve leaflets. Biomacromolecules 11 : 1002-1008, 2010.
26. Ingram JH, Korossis S, Howling G, Fisher J and Ingham E: The use of ultrasonication to aid recellularization of acellular natural tissue scaffolds for use in anterior cruciate ligament reconstruction. Tissue Eng 13: 1561-1572, 2007.

27. Mirsadraee S, Wilcox HE, Korossis SA, Kearney JN, Watterson KG, Fisher J and Ingham E: Development and characterization of an acellular human pericardial matrix for tissue engineering. Tissue Eng 12: 763-773, 2006.

28. Schopka S, Schmid FX, Hirt S, Birnbaum DE, Schmid C and Lehle K: Recellularization of biological heart valves with human vascular cells: In vitro hemocompatibility assessment. J Biomed Mater Res B Appl Biomater 88: 130-138, 2009.

29. Fonseca-Alaniz MH, Takada J, Alonso-Vale MI and Lima FB: Adipose tissue as an endocrine organ: From theory to practice. J Pediatr (Rio J) 83(5 Suppl): S192-S203, 2007.

30. Gilbert TW, Sellaro TL and Badylak SF: Decellularization of tissues and organs. Biomaterials 27: 3675-3683, 2006.

31. Choi JS, Kim BS, Kim JY, Kim JD, Choi YC, Yang HJ, Park K, Lee HY and Cho YW: Decellularized extracellular matrix derived from human adipose tissue as a potential scaffold for allograft tissue engineering. J Biomed Mater Res A 97: 292-299, 2011.

32. Young DA, Ibrahim DO, Hu D and Christman KL: Injectable hydrogel scaffold from decellularized human lipoaspirate. Acta Biomater 7: 1040-1049, 2011.

33. Doran MR, Markway BD, Aird IA, Rowlands AS, George PA, Nielsen LK and Cooper-White JJ: Surface-bound stem cell factor and the promotion of hematopoietic cell expansion. Biomaterials 30: 4047-4052, 2009.

34. Mullen LM, Best SM, Brooks RA, Ghose S, Gwynne JH, Wardale J, Rushton $\mathrm{N}$ and Cameron RE: Binding and release characteristics of insulin-like growth factor-1 from a collagen-glycosaminoglycan scaffold. Tissue Eng Part C Methods 16: 1439-1448, 2010

35. Streuli C: Extracellular matrix remodelling and cellular differentiation. Curr Opin Cell Biol 11: 634-640, 1999.

36. Kim BS, Choi JS,Kim JD, Choi YC and Cho YW: Recellularization of decellularized human adipose-tissue-derived extracellular matrix sheets with other human cell types. Cell Tissue Res 348: 559-567, 2012.

37. Sobral JM, Caridade SG, Sousa RA, Mano JF and Reis RL: Three-dimensional plotted scaffolds with controlled pore size gradients: Effect of scaffold geometry on mechanical performance and cell seeding efficiency. Acta Biomater 7: 1009-1018, 2011.

38. Turner AE, Yu C, Bianco J, Watkins JF and Flynn LE: The performance of decellularized adipose tissue microcarriers as an inductive substrate for human adipose-derived stem cells. Biomaterials 33: 4490-4499, 2012.

This work is licensed under a Creative Commons Attribution-NonCommercial-NoDerivatives 4.0 International (CC BY-NC-ND 4.0) License. 